\title{
Patterns of Nonemergent Visits to Different Healthcare Facilities on the Same Day: A Nationwide Analysis in Taiwan
}

\author{
Meng-Hsuan Wu, ${ }^{1}$ Meng-Ju Wu, ${ }^{2}$ Li-Fang Chou, ${ }^{3}$ and Tzeng-Ji Chen ${ }^{1,4}$ \\ ${ }^{1}$ Institute of Hospital and Health Care Administration, School of Medicine, National Yang-Ming University, \\ Taipei 112, Taiwan \\ ${ }^{2}$ Faculty of Medicine, Semmelweis University, Budapest 1094, Hungary \\ ${ }^{3}$ Department of Public Finance, National Chengchi University, Taipei 116, Taiwan \\ ${ }^{4}$ Department of Family Medicine, Taipei Veterans General Hospital, Taipei 112, Taiwan
}

Correspondence should be addressed to Tzeng-Ji Chen; tjchen@vghtpe.gov.tw

Received 20 January 2014; Accepted 2 April 2014; Published 22 April 2014

Academic Editor: Javier Garcia Campayo

Copyright ( 2014 Meng-Hsuan Wu et al. This is an open access article distributed under the Creative Commons Attribution License, which permits unrestricted use, distribution, and reproduction in any medium, provided the original work is properly cited.

\begin{abstract}
Doctor shopping is a common phenomenon in many countries. However, patterns of switching healthcare facilities on the same day were little known. The data were obtained from the longitudinal cohort datasets (LHID2010) of Taiwan's National Health Insurance Research Database in 2010. Of 1,000,000 persons of the cohort with 13,276,928 nonemergent visits, 185,347 patients had visited different healthcare facilities within one day, with a total of 672,478 visits and 337,260 switches between facilities in 329,073 patientdays. While $63.0 \%(n=212,590)$ of all switches occurred between facilities of the same accreditation level, $14.1 \%(n=47,664)$ moved from lower to higher level, and 22.8\% $(n=77,006)$ moved in the opposite direction. In 33,689 switches, patients moved to the same specialty of another facility. In 48,324 switches, patients moved to another facility with the same diagnosis, and the most frequent diagnoses were diseases of the digestive system $(11,148)$ and diseases of the respiratory system $(10,393)$. In a densely populated country without strict referral regulation, a high percentage of Taiwanese people had the experience of visiting different healthcare facilities on the same day. The system of family physicians as personal doctors and gatekeepers to healthcare might ameliorate the harmful impact.
\end{abstract}

\section{Introduction}

Doctor shopping is a common phenomenon in many countries of the world [1-4] and has been also observed in Taiwan $[5,6]$. Unlike healthcare systems in most developed countries, the National Health Insurance (NHI) in Taiwan does not have a formal gatekeeper system with restrictive regulations in referral, leading to annual number of ambulatory care visits per inhabitant as high as 13.4 and the incubation of doctor shopping behavior [5]. The analyses of doctor shopping in Taiwan have been applied to acute illness (upper respiratory tract infection) [7], chronic diseases (hypertension and type 2 diabetes mellitus) [8], and cancer [6]. In general, doctor shopping is operationally measured as a patient's visits to different physicians or healthcare facilities within a short period of time [5]. Two unique types of doctor shopping in Taiwan have been reported: (1) "one-stop visits" in which a patient pays visits to several specialties of the same healthcare facility within one day [5] and (2) "same-day visits" in which a patient pays visits to different healthcare facilities within one day. While the former phenomenon has been thoroughly analyzed with data mining technique [9], the latter deserves further detailed analysis.

The aim of the current study was to calculate the nationwide prevalence of one patient's visits to different healthcare facilities on the same day within Taiwan's NHI in 2010. More importantly, patterns of switching specialties and healthcare facilities on the same day would be analyzed. The findings might provide evidence for discussion in health policymaking. 


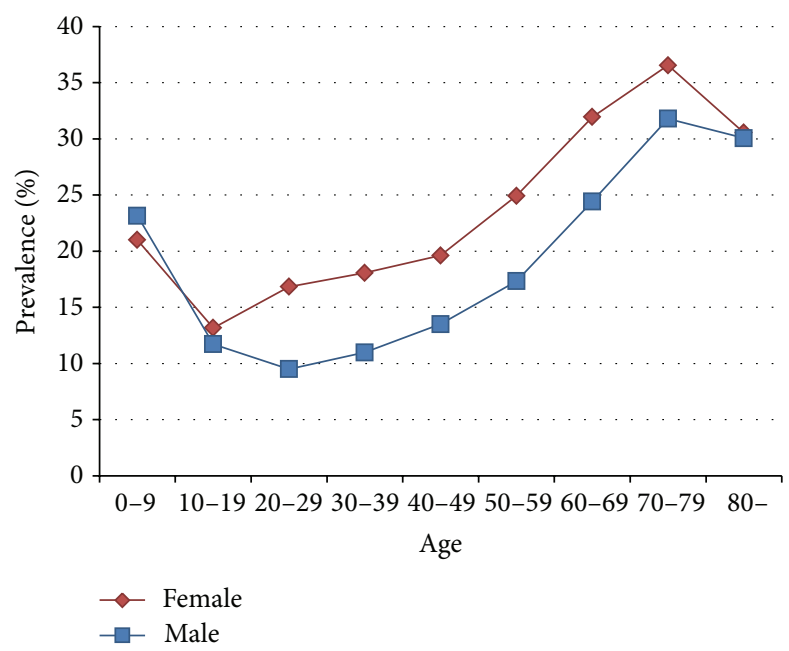

FIGURE 1: Age-sex distribution of patients with visits to different healthcare facilities within one day in the 1,000,000-person cohort in 2010.

\section{Materials and Methods}

The conduct of the study had been approved by the Institutional Review Board of Taipei Veterans General Hospital, Taipei, Taiwan (2013-01-005E).

2.1. Data Sources. The data were obtained from the longitudinal cohort datasets of 1,000,000 beneficiaries (LHID2010) of the National Health Insurance Research Database (NHIRD), managed by the National Health Research Institutes in Miaoli, Taiwan. These 1,000,000 persons were randomly sampled from 23,251,700 persons who had been insured under the NHI in 2010 (http://nhird.nhri.org.tw/date_cohort.htm). The claims belonging to the cohort were extracted from the whole database to form a specific dataset for research use. According to the NHIRD, the cohort did not differ from the population in the distributions of age, sex, and income subject to premium. In the current study, only the datasets of ambulatory visits in 2010 were used. One record of an ambulatory visit contains the patient's data (identification number, sex, birthday, visit date, and three diagnoses) and the provider's data (identification number of the healthcare facility and visited specialty). The original identification number of every beneficiary and healthcare facility has been encrypted in the NHIRD to protect privacy. The uniqueness of each identification number remains after encryption. The master file of healthcare facilities (HOSB) was used to know the level of accreditation.

2.2. Study Design. In 2010, the 1,000,000-person cohort had $15,431,528$ ambulatory visit records. We calculated only those visits with physician consultations of western medicine (WM), dentistry, and traditional Chinese medicine (TCM). The visits to emergency departments were excluded from analysis.

The focus in the current study was on the patients who visited two or more healthcare facilities on the same day. The percentage of these patients in the cohort was computed and also stratified by age and sex. The number of visits involved in multiple visits to different healthcare facilities on the same day was additionally calculated.

Furthermore, we analyzed the patterns of multiple visits to different healthcare facilities on the same day by comparing the accreditation level of healthcare facility, type of visited specialty, and primary diagnosis in each visit with those in the ensuing visit. The sequence numbers of visits embedded in each patient's NHI chip card were used to clarify the direction of a patient's flow from one facility to another, from one specialty to another, and from one diagnosis to another. Four accreditation levels of healthcare facilities exist in Taiwan: academic medical center, metropolitan hospital, local community hospital, and physician clinic. The specialization in Taiwan includes 43 major specialties and 22 subspecialties. To simplify the analysis, the diagnosis in coding of International Classification of Diseases, Ninth Revision, Clinical Modification (ICD-9-CM), was grouped into the chapter of ICD-9-CM. Because a patient might move to and fro between healthcare facilities on the same day, we calculated only the first switch between any two facilities. Because a patient might visit more than one specialty in a facility, we compared only the last specialty of the outgoing facility with the first specialty of the incoming facility. The same method applied to the comparison between diagnoses.

2.3. Data Processing and Statistical Analysis. The Microsoft SQL Server 2012 was used for computing. The regular statistics were displayed. In calculating the percentages of patients in each age-sex group, the dominators were taken from the registry for 1,000,000 beneficiaries in 2010 .

\section{Results}

Of 1,000,000 persons (507,577 women and 492,423 men) of the cohort with $13,276,928$ valid visits, 185,347 patients 


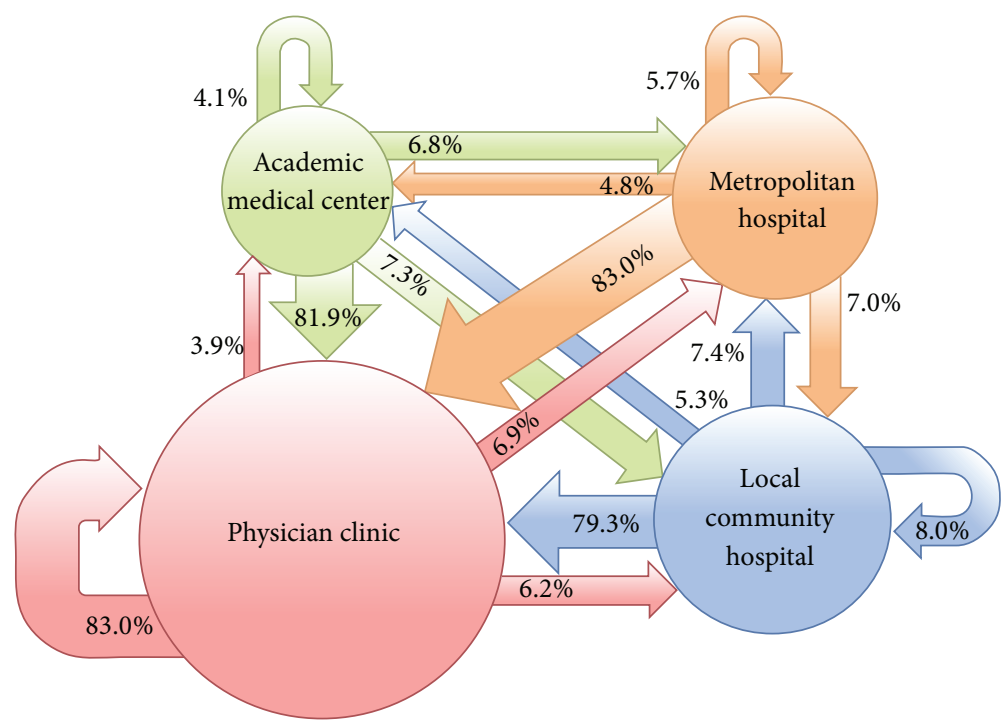

FIGURE 2: Flow of patients with visits to different accreditation level of healthcare facilities within one day in the 1,000,000-person cohort in 2010 .

(107,118 women and 78,229 men) had visited different healthcare facilities within one day in 2010 , with a total of 672,478 visits in 329,073 patient-days. The average age was $42.6 \pm$ 22.8 years $(43.1 \pm 21.7$ in women and $41.9 \pm 24.2$ in men). Except in age group 0-9, women were more likely to visit different healthcare facilities within one day than men. Besides, children under 10 and old people of both sexes had a higher percentage of this phenomenon, with the peak in age group 70-79 (Figure 1). The overwhelming majority (97.6\%, $n=321,258)$ of 329,073 patient-days with visits to different facilities within one day involved only two facilities, but in 30 cases a patient visited 6 facilities within one day (Table 1). On the other hand, $6.8 \%(n=22,393)$ of 329,073 patient-days involved only one specialty; that is, a patient visited the same specialty of different facilities on the same day. In 2 extreme cases, a patient visited 7 specialties within one day (Table 1).

3.1. Distribution by Accreditation Level of Healthcare Facility. Of 329,073 patient-days with visits to different facilities within one day, there were 337,260 switches from one facility to the next facility. The largest group $(n=207,358)$ of these switches occurred between different physician clinics. While 63.0\% $(n=212,590)$ of all switches occurred between facilities of the same accreditation level, $14.1 \%(n=47,664)$ moved from a facility of a lower level to another of a higher level, and $22.8 \%(n=77,006)$ moved in the opposite direction (Table 2) (Figure 2).

3.2. Distribution by Category of Specialty. Of 337,260 switches from one facility to the next facility within one day, the most frequent destinations by specialty were family medicine $(45,524$ times), TCM $(42,102)$, and dentistry $(39,231)$. In 33,689 switches, a patient moved to the same specialty of another facility and the most frequent destinations were family medicine $(6,608)$, internal medicine $(3,201)$, dentistry
TABLE 1: Distribution of a patient's visits to different healthcare facilities within one day in the 1,000,000-person cohort in 2010, stratified by numbers of different healthcare facilities and specialties in a day.

\begin{tabular}{lcc}
\hline & $\begin{array}{c}\text { Number of } \\
\text { patient-days }\end{array}$ & Percentage \\
\hline $\begin{array}{l}\text { Number of different healthcare } \\
\text { facilities visited by a patient in a day }\end{array}$ & & \\
6 & 6 & 0.0 \\
5 & 17 & 0.0 \\
4 & 320 & 0.1 \\
3 & 7,472 & 2.3 \\
2 & 321,258 & 97.6 \\
Number of different specialties & & \\
visited by a patient in a day & & \\
7 & 2 & 0.0 \\
6 & 8 & 0.0 \\
5 & 53 & 0.0 \\
4 & 555 & 0.2 \\
3 & 10,609 & 3.2 \\
2 & 295,453 & 89.8 \\
1 & 22,393 & 6.8
\end{tabular}

$(2,160)$, pediatrics $(2,141)$, and traditional Chinese medicine $(1,839)$ (Table 3$)$.

3.3. Distribution by Principal Diagnosis. Of 337,260 switches from one facility to the next facility within one day, the most frequent diagnoses at both outgoing and incoming facilities were diseases of the digestive system, diseases of the respiratory system, and diseases of the nervous system and sense organs. In 48,324 switches, a patient moved to another 
TABLE 2: Distribution of a patient's switches $(n=337,260)$ between different healthcare facilities within one day in the 1,000,000-person cohort in 2010 , stratified by accreditation level of healthcare facility.

\begin{tabular}{|c|c|c|c|c|c|c|}
\hline & \multicolumn{5}{|c|}{ Incoming facilities } & \multirow{2}{*}{ Total } \\
\hline & $\begin{array}{c}\text { Academic medical } \\
\text { center }\end{array}$ & $\begin{array}{c}\text { Metropolitan } \\
\text { hospital }\end{array}$ & $\begin{array}{c}\text { Local community } \\
\text { hospital }\end{array}$ & Physician clinic & Home care & \\
\hline \multicolumn{7}{|l|}{ Outgoing facilities } \\
\hline Academic medical center & 1,010 & 1,672 & 1,788 & 20,178 & 0 & 24,648 \\
\hline Metropolitan hospital & 1,660 & 1,973 & 2,419 & 28,719 & 0 & 34,771 \\
\hline Local community hospital & 1,471 & 2,066 & 2,249 & 22,229 & 1 & 28,016 \\
\hline Physician clinic & 9,736 & 17,362 & 15,369 & 207,358 & 0 & 249,825 \\
\hline Home care & 0 & 0 & 0 & 0 & $\mathbf{0}$ & 0 \\
\hline Total & 13,877 & 23,073 & 21,825 & 278,484 & 1 & 337,260 \\
\hline
\end{tabular}

facility with the same diagnosis and the most frequent diagnoses were diseases of the digestive system $(11,148)$ and diseases of the respiratory system $(10,393)$ (Table 4$)$.

\section{Discussion}

In our current study, we extended the traditional analyses to observe dynamic changes of patient visits in a large-scale, population-based dataset. Our study was purely descriptive. Although not qualitative in study design, our quantitative analysis did offer some clues.

Firstly, about one fifth of the Taiwanese had experience of switching healthcare facilities on the same day in a year and such visits accounted for $5.1 \%$ of all ambulatory care visits. Because there was neither formal referral system nor strict referral regulation within the NHI in Taiwan, the freedom of choosing healthcare facilities [10] and the low copayments [11, 12] might contribute to the occurrence of this phenomenon. The longer opening hours of healthcare facilities with walk-in registration [13] on the supply side might also play a role.

Secondly, of all switches on the same day, 16,308 (4.8\%) occurred between hospitals. Usually the outpatient clinic of a hospital in Taiwan offered a broad spectrum of specialties so that the patients could consult several specialties in one visit (the so-called one-stop visit) [14]. For visits to different hospitals within one day, the patients might either search for a second opinion for the same illness or consult different hospitals for different illnesses. That is, a hospital might be good in some specialties and another in some other specialties. Because Taiwan is a densely populated island and most hospitals are located in cities, the patient could thus utilize the efficient transportation system to reach different hospitals in the shortest possible time.

Thirdly, with respect to specialty, 59,332 (17.6\%) switches on the same day occurred between traditional Chinese medicine (TCM) and all specialties of western medicine (WM). Past studies had also revealed that patients in Taiwan might visit WM and TCM one after another within a short time $[15,16]$. TCM can be traced back more than 2,000 years and still commonly used by people in China, Taiwan, Korea, and Japan [17]. More than 9,000 items of TCM herbal drugs are reimbursable within the NHI in Taiwan. Our finding highlights the importance that WM physicians should pay more attention to TCM drugs taken by patients to avoid drug interaction $[5,18,19]$.

Furthermore, among switches on the same day with the same diagnosis, the most frequent diagnoses were diseases of the digestive system and diseases of the respiratory system. One of our earlier studies has revealed that these two kinds of diseases accounted for almost a half of ambulatory care visits in Taiwan and the number of visits with diseases of the respiratory system was twice that with diseases of digestive system [5]. However, in our current study, diseases of digestive system caused switches on the same day more frequently than diseases of the respiratory system. Perhaps diseases of digestive system bring more stress to patients. The reason deserves further analysis.

Our study with insurance claims of the NHIRD had some limitations. Firstly, the beneficiary's residence was unknown. The influence of location could not be studied. Secondly, we did not measure the distance between healthcare facilities that a patient visited on the same day. The traffic situation was not taken into consideration, either. Thirdly, the patient's complaints, symptoms, or reasons for consultations were not available. We could not know whether the switches between healthcare facilities were initiated by formal or informal referral from physicians, either.

\section{Conclusion}

In a densely populated country without strict referral regulation, a high percentage of Taiwanese people had the experience of visiting different healthcare facilities on the same day. It might represent the efficiency of Taiwan's NHI. However, in absence of communication between healthcare suppliers, the resulting duplicate examination and treatment might bring about problems of financial burden and patient safety. The system of family physicians as personal doctors and gatekeepers to healthcare might ameliorate the harmful impact [20]. 


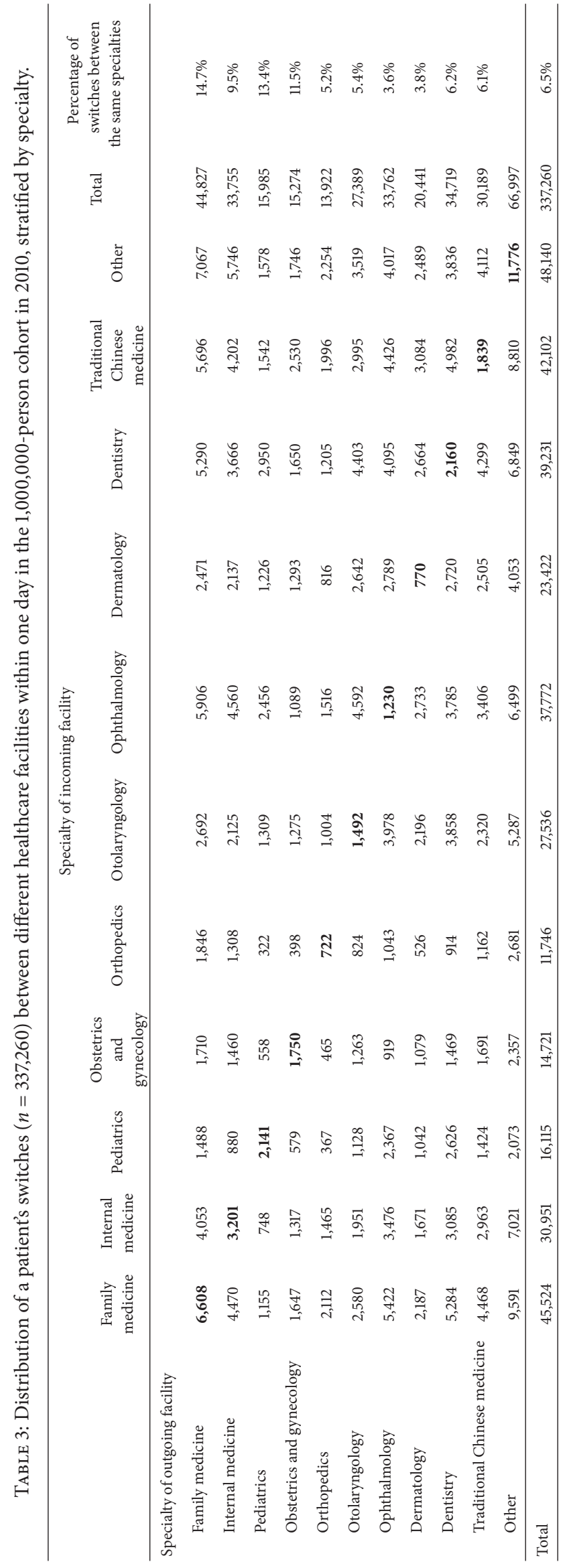




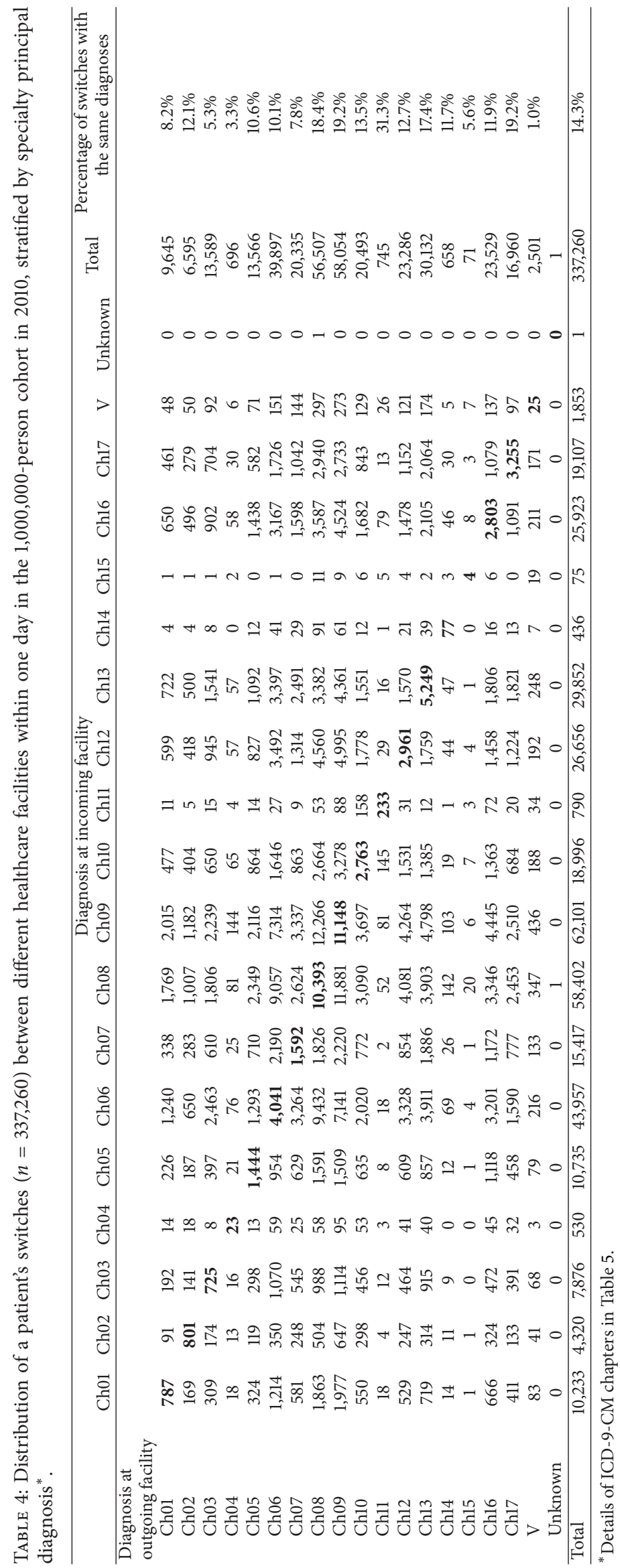


TABle 5

\begin{tabular}{|c|c|c|}
\hline Chapter & Diagnosis & $\begin{array}{l}\text { Code range in } \\
\text { ICD-9-CM }\end{array}$ \\
\hline Ch01 & Infectious and parasitic diseases & $001-139$ \\
\hline Ch02 & Neoplasms & $140-239$ \\
\hline Ch03 & $\begin{array}{l}\text { Endocrine, nutritional, and } \\
\text { metabolic diseases and immunity } \\
\text { disorders }\end{array}$ & $240-279$ \\
\hline Ch04 & $\begin{array}{l}\text { Diseases of the blood and } \\
\text { blood-forming organs }\end{array}$ & $280-289$ \\
\hline Ch05 & Mental disorders & $290-319$ \\
\hline Ch06 & $\begin{array}{l}\text { Diseases of the nervous system and } \\
\text { sense organs }\end{array}$ & $320-389$ \\
\hline Ch07 & Diseases of the circulatory system & $390-459$ \\
\hline Ch08 & Diseases of the respiratory system & $460-519$ \\
\hline Ch09 & Diseases of the digestive system & $520-579$ \\
\hline Ch10 & $\begin{array}{l}\text { Diseases of the genitourinary } \\
\text { system }\end{array}$ & $580-629$ \\
\hline Chl1 & $\begin{array}{l}\text { Complications of pregnancy, child } \\
\text { birth, and the puerperium }\end{array}$ & $630-677$ \\
\hline Ch12 & $\begin{array}{l}\text { Diseases of the skin and } \\
\text { subcutaneous tissue }\end{array}$ & $680-709$ \\
\hline Ch13 & $\begin{array}{l}\text { Diseases of the musculoskeletal } \\
\text { system and connective tissue }\end{array}$ & $710-739$ \\
\hline Ch14 & Congenital abnormalities & $740-759$ \\
\hline Ch15 & $\begin{array}{l}\text { Certain conditions originating in } \\
\text { the perinatal period }\end{array}$ & $760-779$ \\
\hline Ch16 & $\begin{array}{l}\text { Symptoms, signs, and ill-defined } \\
\text { conditions }\end{array}$ & $780-799$ \\
\hline Ch17 & Injury and poisoning & $800-999$ \\
\hline $\mathrm{V}$ & $\begin{array}{l}\text { Supplementary classification of } \\
\text { factors influencing health status and } \\
\text { contact with health services }\end{array}$ & V01-V82 \\
\hline
\end{tabular}

\section{Conflict of Interests}

The authors declare that there is no conflict of interests regarding the publication of this paper.

\section{Acknowledgments}

This study is based in part on data from the National Health Insurance Research Database provided by the Bureau of National Health Insurance, Department of Health, and managed by National Health Research Institutes. The interpretation and conclusions contained herein do not represent those of the Bureau of National Health Insurance, Department of Health, or the National Health Research Institutes. This study was supported by Grants from the National Science Council (NSC 100-2410-H-010-001-MY3) and Taipei Veterans General Hospital (V103E10-001).

\section{References}

[1] M. S. Cepeda, D. Fife, L. Vo, G. Mastrogiovanni, and Y. Yuan, "Comparison of opioid doctor shopping for tapentadol and oxycodone: a cohort study," Journal of Pain, vol. 14, no. 2, pp. 158-164, 2013.

[2] K. W. Hariman, S. C. Lam, Y. W. S. Lam, K. H. K. Luk, K. K. Poon, and A. M. Li, "Fever as a predictor of doctor shopping in the paediatric population," Hong Kong Medical Journal, vol. 19, no. 1, pp. 6-12, 2013.

[3] J. Norton, G. De Roquefeuil, M. David, J.-P. Boulenger, K. Ritchie, and A. Mann, "The mental health of doctor-shoppers: experience from a patient-led fee-for-service primary care setting," Journal of Affective Disorders, vol. 131, no. 1-3, pp. 428432, 2011.

[4] T. Sato, "Doctor-shopping patients and users of alternative medicine among Japanese primary care patients," General Hospital Psychiatry, vol. 17, no. 2, pp. 115-125, 1995.

[5] T.-J. Chen, L.-F. Chou, and S.-J. Hwang, "Patterns of ambulatory care utilization in Taiwan," BMC Health Services Research, vol. 6, article 54, 2006.

[6] C. I. Hsieh, K. P. Chung, M. C. Yang, and T. C. Li, "Association of treatment and outcomes of doctor-shopping behavior in patients with hepatocellular carcinoma," Patient Preference and Adherence, vol. 7, pp. 693-701, 2013.

[7] M.-J. Wang and S.-P. Lin, "Study on doctor shopping behavior: insight from patients with upper respiratory tract infection in Taiwan," Health Policy, vol. 94, no. 1, pp. 61-67, 2010.

[8] M. C. Kuo, C. Jeng, C. M. Chen, and W. S. Jian, "Profile of elderly with multiple physician visits: advocacy for tailored comprehensive geriatric assessment use in clinics," Geriatrics \& Gerontology International, vol. 14, no. 2, pp. 372-380, 2013.

[9] C.-Y. Tu, T.-J. Chen, and L.-F. Chou, "Application of frequent itemsets mining to analyze patterns of One-Stop visits in Taiwan," PLoS ONE, vol. 6, no. 7, Article ID e14824, 2011.

[10] S.-H. Cheng, Y.-F. Hou, and C.-C. Chen, "Does continuity of care matter in a health care system that lacks referral arrangements?" Health Policy and Planning, vol. 26, no. 2, pp. 157-162, 2011.

[11] J.-H. Huang and C.-M. Tung, "The effects of outpatient copayment policy on healthcare usage by the elderly in Taiwan," Archives of Gerontology and Geriatrics, vol. 43, no. 1, pp. 101-116, 2006.

[12] L.-C. Chen, E. I. Schafheutle, and P. R. Noyce, "The impact of nonreferral outpatient co-payment on medical care utilization and expenditures in Taiwan," Research in Social and Administrative Pharmacy, vol. 5, no. 3, pp. 211-224, 2009.

[13] H.-F. Chen, C.-H. Lee, and R.-E. Chang, "Workload of attending physicians at an academic center in Taiwan," Journal of the Chinese Medical Association, vol. 73, no. 8, pp. 425-430, 2010.

[14] C.-C. Shao, C.-P. Chang, L.-F. Chou, T.-J. Chen, and S.-J. Hwang, "The ecology of medical care in Taiwan," Journal of the Chinese Medical Association, vol. 74, no. 9, pp. 408-412, 2011.

[15] C.-C. Shih, Y.-C. Su, C.-C. Liao, and J.-G. Lin, "Patterns of medical pluralism among adults: results from the 2001 national health interview survey in Taiwan," BMC Health Services Research, vol. 10, article 191, 2010.

[16] L.-C. Chang, N. Huang, Y.-J. Chou, C.-H. Lee, F.-Y. Kao, and Y.-T. Huang, "Utilization patterns of Chinese medicine and Western medicine under the National Health Insurance Program in Taiwan, a population-based study from 1997 to 2003," BMC Health Services Research, vol. 8, article 170, 2008. 
[17] M.-J. Huang and M.-Y. Chen, "Integrated design of the intelligent web-based Chinese Medical Diagnostic System (CMDS) systematic development for digestive health," Expert Systems with Applications, vol. 32, no. 2, pp. 658-673, 2007.

[18] M.-H. Hsu, Y.-T. Yeh, C.-Y. Chen, C.-H. Liu, and C.-T. Liu, "Online detection of potential duplicate medications and changes of physician behavior for outpatients visiting multiple hospitals using national health insurance smart cards in Taiwan," International Journal of Medical Informatics, vol. 80, no. 3, pp. 181-189, 2011.

[19] F.-P. Chen, T.-J. Chen, Y.-Y. Kung et al., "Use frequency of traditional Chinese medicine in Taiwan," BMC Health Services Research, vol. 7, article 26, 2007.

[20] J. McCormick, "Death of the personal doctor," The Lancet, vol. 348, no. 9028, pp. 667-668, 1996. 


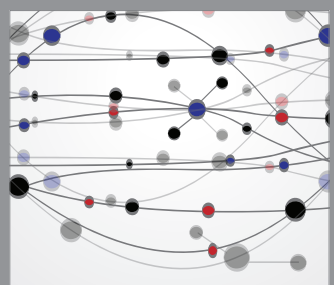

The Scientific World Journal
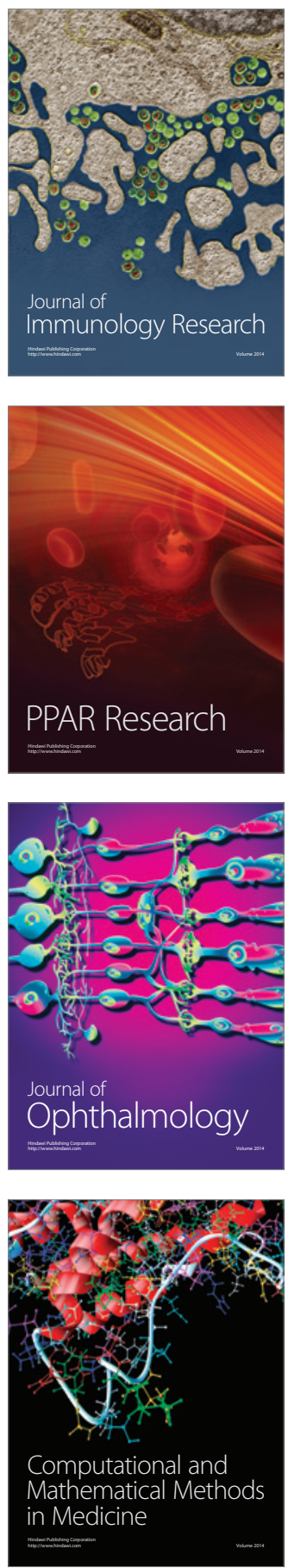

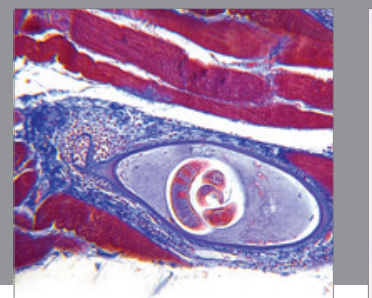

Gastroenterology

Research and Practice
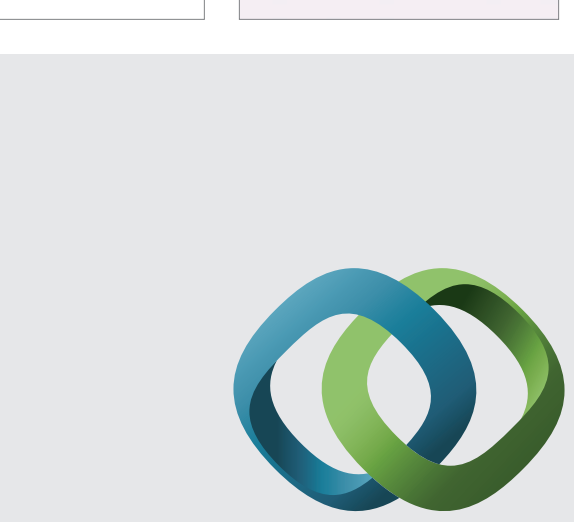

\section{Hindawi}

Submit your manuscripts at

http://www.hindawi.com
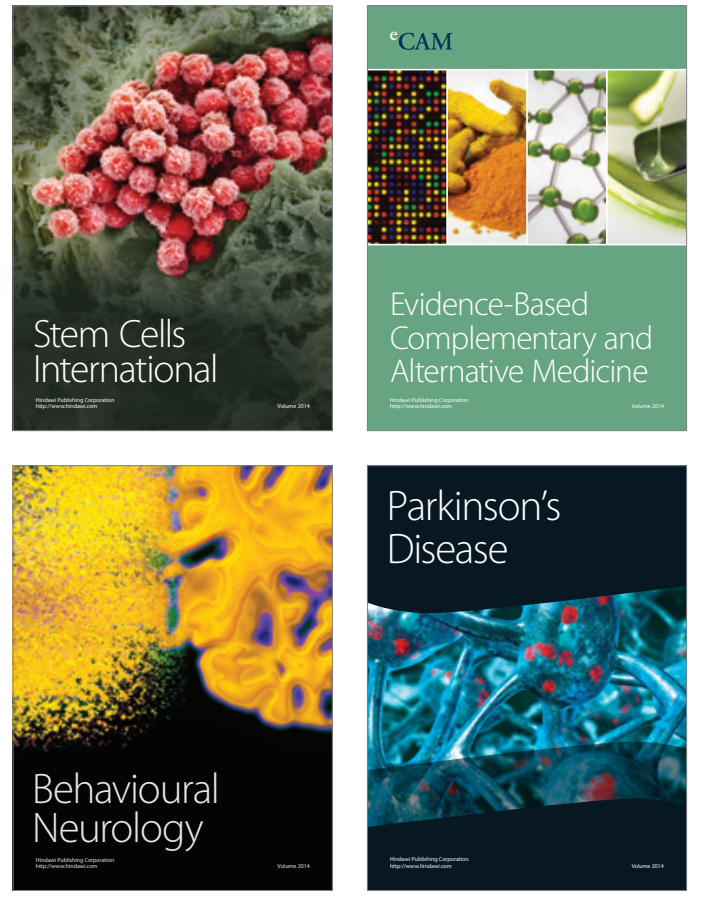
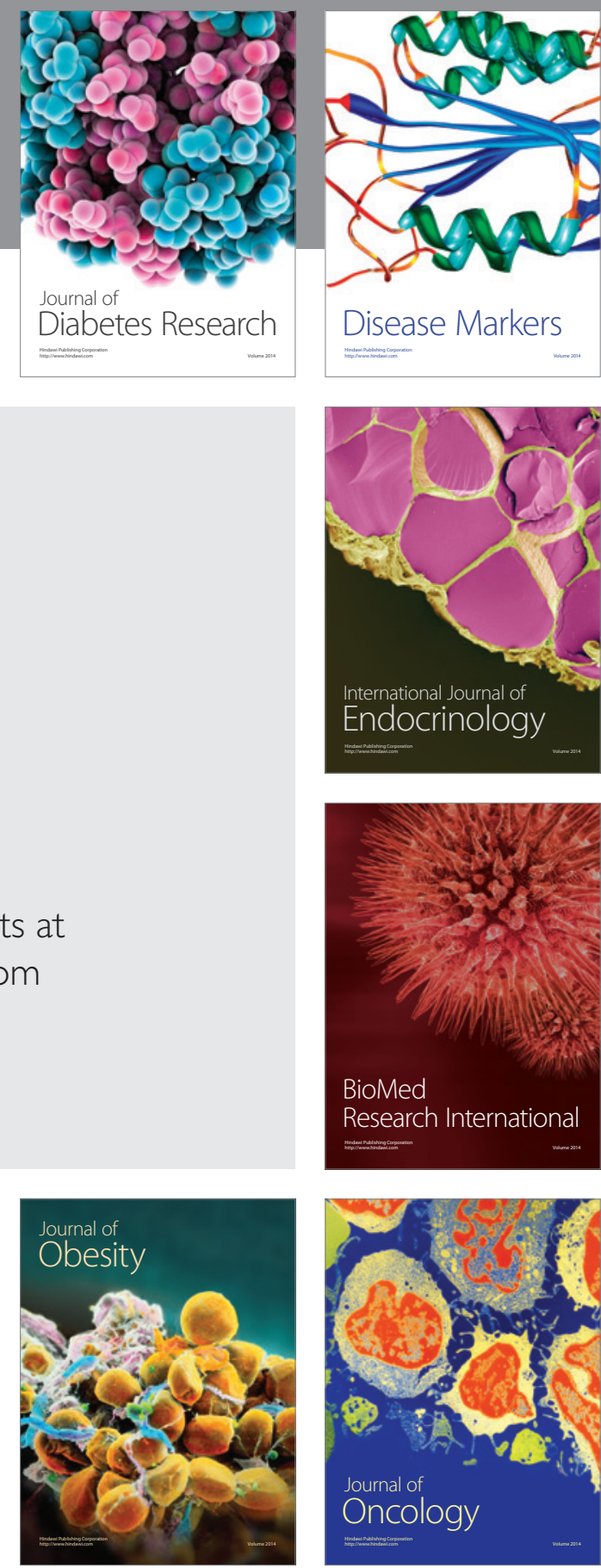

Disease Markers
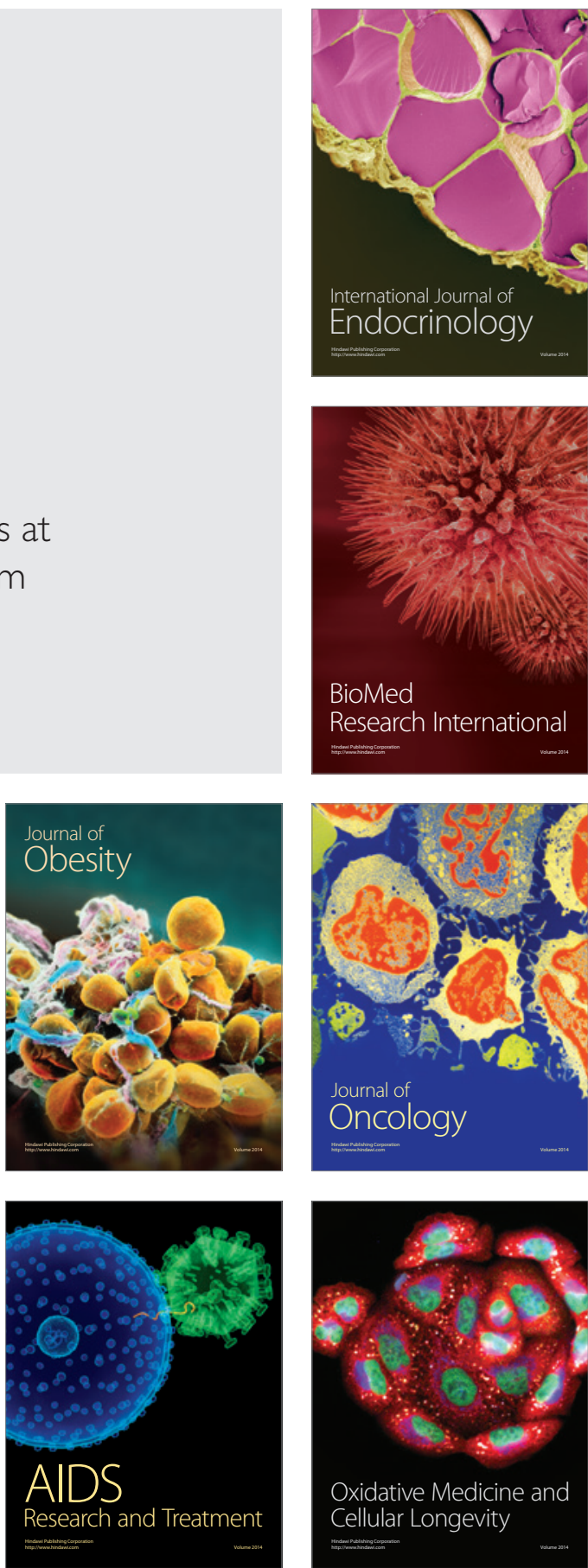